\title{
Cost-effectiveness of injectable opioid treatment $v$. oral methadone for chronic heroin addiction ${ }^{\dagger}$
}

\author{
Sarah Byford, Barbara Barrett, Nicola Metrebian, Teodora Groshkova, Maria Cary, Vikki Charles, \\ Nicholas Lintzeris and John Strang
}

\section{Background}

Despite evidence of the effectiveness of injectable opioid treatment compared with oral methadone for chronic heroin addiction, the additional cost of injectable treatment is considerable, and cost-effectiveness uncertain.

\section{Aims \\ To compare the cost-effectiveness of supervised injectable heroin and injectable methadone with optimised oral methadone for chronic refractory heroin addiction.}

\section{Method}

Multisite, open-label, randomised controlled trial. Outcomes were assessed in terms of quality-adjusted life-years (QALYS). Economic perspective included health, social services and criminal justice resources.

\section{Results}

Intervention costs over 26 weeks were significantly higher for injectable heroin (mean $£ 8995 \mathrm{~V}$. $£ 4674$ injectable methadone and $£ 2596$ oral methadone; $P<0.0001)$. Costs overall were highest for oral methadone (mean $£ 15805 \mathrm{~V}$. £13410 injectable heroin and $£ 10945$ injectable methadone; $P=$ n.s.) due to higher costs of criminal activity. In cost-effectiveness analysis, oral methadone was dominated by injectable heroin and injectable methadone (more expensive and less effective). At willingness to pay of $£ 30000$ per QALY, there is a higher probability of injectable methadone being more cost-effective (80\%) than injectable heroin.

\section{Conclusions}

Injectable opioid treatments are more cost-effective than optimised oral methadone for chronic refractory heroin addiction. The choice between supervised injectable heroin and injectable methadone is less clear. There is currently evidence to suggest superior effectiveness of injectable heroin but at a cost that policy makers may find unacceptable. Future research should consider the use of decision analytic techniques to model expected costs and benefits of the treatments over the longer term.

\section{Declaration of interest}

J.S. and N.L. have contributed to UK National Treatment Agency for Substance Misuse and Department of Health guidelines on the role of injectable prescribing in the management of opiate addiction (2003; chaired by J.S.). J.S. has chaired the broader-scope pan-UK working group preparing the 2007 Orange Guidelines for the UK Departments of Health, providing guidance on management and treatment of drug dependence and misuse. J.S. has provided consultancy advice on possible novel opiate addiction treatments, products and formulations to Britannia/ Genus, Auralis/Viropharma, and Martindale Pharmaceuticals, and other pharmaceutical companies. J.S. and his institution have received support and funding from the Department of Health (England) and National Treatment Agency (England); and J.S. has close associations with the charity Action on Addiction. N.L. has received honoraria, travel and conference support, and consultancy fees from Reckitt Benckiser and Schering-Plough. N.L. has an untied educational grant for research related to buprenorphine in the management of opioid dependence. J.S., N.L. and N.M. have previously undertaken a research study of British heroin policy and have given varied commentaries and contributed to professional and public debate.
Heroin addiction is commonly treated with oral methadone maintenance substitution, but about $5-10 \%$ of people addicted to heroin who remain in treatment fail to benefit and continue to inject heroin on a regular basis. ${ }^{1}$ For this chronic group who persistently fail to benefit from conventional treatments, evidence is emerging to support the effectiveness of maintenance treatment with supervised medicinal heroin (diamorphine) as a second-line treatment for chronic heroin addiction. ${ }^{2}$ Injectable opioid treatment with methadone or diamorphine has historically been provided only in the $\mathrm{UK}^{3}$ but an adapted form has recently been trialled in a number of countries, including Switzerland, ${ }^{4}$ Germany ${ }^{5}$ and Canada, ${ }^{6}$ as well as the UK. ${ }^{7}$ Supervised injectable treatments are considerably more expensive than oral methadone treatment, requiring more expensive medications ${ }^{8}$ and additional dispensing and supervision resources, ${ }^{9}$ with evidence to suggest that they may be four to five times more expensive to deliver. ${ }^{10}$ Given increasing resource pressures on health services, injectable treatments may be viewed as an unaffordable luxury. However, value for money is also influenced by treatment outcomes and cost

†See editorial, pp. 325-326, this issue. savings elsewhere in the health service or wider community. With the economic and social costs of Class A drug use estimated to be over $£ 15$ billion in England and Wales in $2003 / 04,{ }^{11}$ the potential for cost savings as a result of alternative treatment options should be explored. We present cost-effectiveness data from the Randomised Injectable Opiate Treatment Trial (RIOTT), described in detail elsewhere, ${ }^{7,9}$ comparing supervised injectable heroin or injectable methadone with optimised oral methadone for chronic refractory heroin addiction in patients not responding to current oral maintenance treatment.

\section{Method}

\section{Patients and study design}

People with chronic heroin addiction (aged 18-65 years) receiving conventional oral methadone maintenance treatment $(\geqslant 6$ months) were eligible for the study if they were continuing to inject 'street' heroin regularly $(\geqslant 50 \%$ of days in preceding 3 months). Patients were recruited between September 2005 and 
August 2008 from supervised injecting clinics in three sites across England (south London, Darlington and Brighton). Patients provided written informed consent and ethical approval was received from the London Multi-site Research Ethics Committee.

\section{Randomisation and masking}

Randomisation was undertaken by an independent clinical trials unit using minimisation to assign patients to: supervised injectable heroin (injectable heroin), supervised injectable methadone (injectable methadone), or optimised oral methadone (oral methadone). Randomisation was stratified for: regular cocaine or 'crack' cocaine use ( $\geqslant 50 \%$ of days in previous 30 days); previous treatment with optimised oral methadone $(\geqslant 80 \mathrm{mg}$ daily; supervised $\geqslant 5$ days per week); and clinic site (south London, Darlington or Brighton). In this open-label study, researchers were unmasked to treatment allocation after randomisation.

\section{Treatments}

Supervised injectable heroin consisted of twice daily individually titrated injected heroin doses (typically stabilising at 300$600 \mathrm{mg} /$ day, to a maximum of $900 \mathrm{mg} /$ day). Supervised injectable methadone consisted of once daily individually titrated injected methadone (maximum $200 \mathrm{mg} /$ day). All injected doses were self-administered under direct nursing supervision at clinic sites. Oral methadone was additionally prescribed to patients receiving injectable treatment to prevent overnight withdrawal, or if the patient could not attend the clinic for their usual injected doses. Optimised oral methadone consisted of once daily individually titrated doses of $\geqslant 80 \mathrm{mg}$ consumed under direct nursing supervision at clinic sites on $\geqslant 5$ days per week, with takeaway doses for weekends. All patients were assigned a case worker for scheduled weekly counselling, monthly medical reviews and access to psychological services. Patients received their allocated treatment for 26 weeks.

\section{Outcome measures}

Outcomes were assessed at baseline, 14 and 26 weeks after trial entry. The primary clinical outcome was proportion of participants negative for street heroin in at least $50 \%$ of weekly random urine tests during weeks 14-26 ('responders'). 7,9 The economic outcome measure was quality-adjusted life-years (QALYs), calculated from the EQ-5D measure of health-related quality of life, ${ }^{12}$ using the area under the curve approach. ${ }^{13}$ The EQ-5D has been shown to be a valid generic measure of outcome in heroin-dependent populations. ${ }^{14}$ Cost-effectiveness was explored in relation to both measures of outcome, however results were similar so only those using QALYs are reported here.

\section{Resource use and costs}

The economic evaluation took a broad perspective, including all health and social services, plus the criminal justice sector. Detailed information on resources associated with the three treatments, including medications, equipment, dispensing services, urine tests and contacts with medical, key worker and psychology staff, were recorded for each individual at each clinic. Resources external to the clinics, including supported (staffed) accommodation, health, social services and criminal justice sector contacts and crimes committed were collected during the interview with participants at baseline (covering the previous 6 months) and at 14- and 26-week follow-up. Data were collected using a modified version of the
Adult Service Use Schedule (AD-SUS), previously developed by the authors with substance-misusing populations. ${ }^{15}$

All unit costs were for the financial year 2007/08, to correspond with the final recruitment year of the trial. This approach helps to maximise the relevance of the unit costs to the population in the trial and the services they were provided with at the time the trial took place. No adjustments were made for inflation, so these costs may underestimate the costs of providing the same treatment to a current population. However, the relative cost differences between the two groups, on which the statistical analyses are based, should not be greatly affected.

Intervention costs were calculated using a standard microcosting approach, ${ }^{16}$ with adjustments to reflect the long-term costs of a RIOTT clinic in routine clinical practice, as follows.

\section{Drug costs}

The costs of oral and injectable methadone were taken from the British National Formulary. ${ }^{8}$ The cost of injectable heroin was the price paid by the RIOTT clinics at the end of the trial, representing the most efficient market price following negotiations and supplier changes during the trial.

\section{Clinic costs}

Clinic costs were based on annual budgets for the year 2007/08, reflecting the most efficient cost structure achieved following supplier and staff adjustments as the clinics evolved over the course of the trial. In addition, efficiency savings achieved by the longest running clinic (London) were applied to the budgets of the other two clinics, where this was believed to reflect the most likely pattern of future supply. A cost-per-hour for clinic staff was calculated on the basis of salary and employer costs plus overheads (utilities, support staff, buildings, management, etc.), weighted to take into account the ratio of time spent in direct contact with clients to time spent on other activities.

\section{Pharmacy costs}

Treatment-specific pharmacy cost weightings were calculated using pharmacist estimates of time spent ordering, preparing and managing the distribution of each of the three treatments.

\section{Urine test costs}

Random urine tests to detect papaverine and noscapine use in all three groups were taken weekly. ${ }^{7,17}$ However, the research team estimated that bi-weekly tests would be more likely in routine practice and tests for street heroin (rather than the cheaper test for opiate use) would only be undertaken for those receiving injectable heroin, so treatment costs were adjusted accordingly.

\section{Nationally applicable unit costs}

These were applied to all health and social care contacts, criminal justice system contacts and criminal activity ${ }^{18-22}$ as well as supported accommodation, including residential care, residential rehabilitation, hostels and shelters. ${ }^{19}$

\section{Analysis}

Economic analysis was carried out on an intention-to-treat basis using an analysis plan drawn up prior to data analysis. Primary analyses compared cost and cost-effectiveness at 26-week follow-up of (a) injectable heroin $v$. oral methadone, and (b) injectable $v$. oral methadone, in line with the primary aims 
of the study. ${ }^{7}$ Secondary analyses explored injectable heroin $v$. injectable methadone $v$. oral methadone in a three-way comparison.

Analyses compared mean costs using standard parametric $t$-tests or analysis of covariance with covariates for pre-specified baseline minimisation factors: site (London, Darlington, Brighton), regular cocaine/crack user (yes/no) and currently receiving optimised oral methadone (yes/no). The robustness of the parametric tests was confirmed using bias-corrected, nonparametric bootstrapping. ${ }^{23}$ To avoid excessive significance testing, resource use items were not tested for statistical significance.

Cost-effectiveness was assessed through the calculation of incremental cost-effectiveness ratios (ICERs) - the additional cost of one intervention compared with another divided by the additional effects. For the three-way comparison, ICERs were calculated using rules of dominance and extended dominance. ${ }^{24}$ Interventions were ranked by cost, from the least to most expensive, and dominated interventions (more expensive and less effective than the previous strategy) were excluded from further analysis. This process compares interventions in terms of observed differences, regardless of statistical significance.

Non-parametric bootstrapping from the cost and effectiveness data was used to generate a joint distribution of incremental mean costs and effects for the treatments under comparison to explore the probability that each is the optimal choice, subject to a range of maximum values (ceiling ratio) that a decision maker might be willing to pay for an additional QALY. Cost-effectiveness acceptability curves (CEAC), a recommended decision-making approach to dealing with uncertainty, ${ }^{25}$ were generated by plotting these probabilities for a range of values of the ceiling ratio. ${ }^{26}$

One-way sensitivity analysis was used to explore (a) the impact of hypothesised variations in the price of pharmaceutical heroin, and (b) the narrower National Health Service (NHS)/ personal social services perspective preferred for the National Institute for Health and Care Excellence (NICE) reference case. ${ }^{27}$ The National Institute for Health and Care Excellence is responsible for the provision of guidance and advice to improve health and social care in the UK and thus this perspective is of particular relevance to a UK audience. The main analysis, however, will be of value to a broader international audience where guidelines for economic perspectives are known to vary. ${ }^{28}$ Single imputation using multiple regression was used for missing total cost data, missing for only $5.5 \%$ of the sample $(n=7)$. EQ-5D data, missing for only $4 \%$ of the sample $(n=5)$, was imputed conservatively on the basis of last value carried forward.

\section{Results}

\section{Participants}

Of 301 patients screened for eligibility, 127 were randomly allocated to supervised injectable heroin $(n=43)$, supervised injectable methadone $(n=42)$ or optimised oral methadone $(n=42)$. Full economic data were available for $94.5 \%$ of the sample $(n=120)$. Most participants were men $(n=93,73 \%)$, White $(n=122,96 \%)$ and unemployed $(n=121,95 \%)$, had spent time in prison $(n=93,73 \%)$, and had a mean age of 37.2 years (s.d. =6.5). Participants had used opiates for a mean of 16.6 years (s.d. $=7.3$ ), had injected drugs for a mean of 13.7 years (s.d. $=7.8$ ) and had received treatment for a mean of 9.8 years (s.d. $=6.7)$. The full trial profile and description of the participants has been published elsewhere. ${ }^{7,9}$

\section{Resource use}

Mean use of resources is summarised in online Table DS1. Participants in all groups spent the majority of the 26-week follow-up living independently. Hostels and shelters were used relatively frequently, particularly by the oral methadone group (mean 50 days $v$. 35 days injectable methadone group, 24 days injectable heroin group). Residential rehabilitation and other types of supported accommodation were used relatively infrequently. Participants accessed a wide range of health and social services. The most frequent contacts were with general practitioners and syringe exchanges, the latter being accessed by a larger proportion of the oral $(86 \%)$ and injectable methadone (74\%) groups than the injectable heroin group (39\%). The injectable methadone group spent more nights in prison on average (mean 6.1 nights v. 2.2 nights injectable heroin group, 0.4 nights oral methadone group), but crimes committed were substantially higher for the oral methadone group (mean 21 crimes $v .7$ crimes injectable methadone group, 6 crimes injectable heroin group).

Table 1 provides a breakdown of the total number of each crime committed over the 26-week follow-up. The most common offences committed were theft from shops (23\% of participants committing 493 offences) and handling stolen goods (19\% of participants committing 383 offences). Other crimes committed relatively frequently included begging, theft from a vehicle and soliciting/prostitution, although these crimes were committed by small proportions of the total population (3-5\%). A smaller proportion of the injectable heroin group reported committing any crimes over the follow-up period $(37 \%$ v. $43 \%$ oral methadone group, $45 \%$ injectable methadone group) and the total number of crimes committed was lower in the injectable drug groups (total: 241 crimes injectable heroin, 278 crimes injectable methadone $v .764$ oral methadone).

\section{Costs}

Total intervention costs over the 26-week follow-up were significantly higher on average for the injectable heroin group (mean $£ 8995$ v. $£ 4674$ injectable methadone and $£ 2596$ oral methadone groups; $P<0.0001$ ) (Table 2). There were no significant differences for other resource categories. The total cost of other health, social services and criminal justice resources were

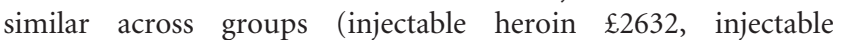

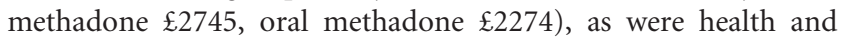
social services alone (injectable heroin $£ 2190$, injectable

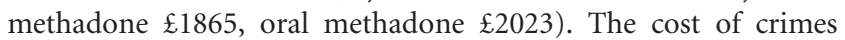
committed varied considerably (injectable heroin $£ 1782$, injectable methadone $\mathfrak{2 3 5 2 6}$, oral methadone $\mathfrak{E} 10962$ ), however these differences were not statistically significant.

Overall, including the cost of the interventions, other services and crimes, the oral methadone group was the most expensive ( $£ 15805)$, followed by the injectable heroin $(£ 13410)$ and methadone (£10 945) groups. From the narrower NHS/personal social services perspective, injectable heroin was the most expensive (£11 186), followed by injectable methadone (£6539) and oral methadone (£4592).

\section{Effectiveness}

In intention-to-treat analysis, a higher proportion of participants in the injectable heroin group $(72 \%)$ were classified as responders (negative for street heroin in $\geqslant 50 \%$ of urine tests in weeks 14-26) than those in the injectable and oral methadone groups (39\% and $27 \%$ respectively). The difference was significant for injectable heroin $v$. oral methadone (odds ratio (OR) 7.42, 95\% CI 2.6920.46, $P<0.0001)$, but not for injectable $v$. oral methadone $(\mathrm{OR}=1.74,95 \%$ CI $0.66-4.60, P=0.264){ }^{7}$ Quality-adjusted lifeyears over the follow-up, reported in Table 3, were also higher 
Table 1 Crimes committed over the 26-week follow-up period

\begin{tabular}{|c|c|c|c|c|c|c|}
\hline & \multicolumn{2}{|c|}{$\begin{array}{l}\text { Supervised injectable heroin } \\
\qquad(n=41)\end{array}$} & \multicolumn{2}{|c|}{$\begin{array}{l}\text { Supervised injectable methadone } \\
\qquad(n=42)\end{array}$} & \multicolumn{2}{|c|}{$\begin{array}{l}\text { Optimised oral methadone } \\
\qquad(n=37)\end{array}$} \\
\hline & $\begin{array}{l}\text { Committing } \\
\text { offence, } n(\%)\end{array}$ & $\begin{array}{l}\text { Total number } \\
\text { of offences }\end{array}$ & $\begin{array}{l}\text { Committing } \\
\text { offence, } n(\%)\end{array}$ & $\begin{array}{l}\text { Total number } \\
\text { of offences }\end{array}$ & $\begin{array}{l}\text { Committing } \\
\text { offence, } n(\%)\end{array}$ & $\begin{array}{l}\text { Total number } \\
\text { of offences }\end{array}$ \\
\hline Theft from shops & $8(20)$ & 137 & $13(31)$ & 129 & $6(16)$ & 227 \\
\hline Handling stolen goods & $9(22)$ & 38 & $7(17)$ & 77 & 7 (19) & 268 \\
\hline Begging & $1(2)$ & 40 & $2(5)$ & 15 & $3(8)$ & 132 \\
\hline Theft from a vehicle & $2(5)$ & 8 & $1(2)$ & 2 & $2(5)$ & 65 \\
\hline Soliciting/prostitution & $1(2)$ & 2 & $2(5)$ & 18 & $1(3)$ & 10 \\
\hline Theft from the person & $0(0)$ & 0 & $2(5)$ & 13 & $1(3)$ & 6 \\
\hline Robbery of personal property & $1(2)$ & 1 & $1(2)$ & 1 & $1(3)$ & 10 \\
\hline Going equipped for stealing & $0(0)$ & 0 & $0(0)$ & 0 & $1(3)$ & 10 \\
\hline Criminal damage to a vehicle & $0(0)$ & 0 & $0(0)$ & 0 & $1(3)$ & 9 \\
\hline Burglary in dwelling & $0(0)$ & 0 & $2(5)$ & 6 & $0(0)$ & 0 \\
\hline Burglary in a building other than a dwelling & $0(0)$ & 0 & $1(2)$ & 3 & $0(0)$ & 0 \\
\hline Robbery of commercial property & $0(0)$ & 0 & $2(5)$ & 2 & $1(3)$ & 1 \\
\hline Criminal damage to a dwelling & $1(2)$ & 1 & $1(2)$ & 2 & $0(0)$ & 0 \\
\hline Breach of peace/drunk and disorderly & $0(0)$ & 0 & $2(5)$ & 2 & $1(3)$ & 1 \\
\hline Common assault & $0(0)$ & 0 & 2 (5) & 2 & $0(0)$ & 0 \\
\hline Theft of a pedal cycle & $0(0)$ & 0 & $0(0)$ & 0 & $1(3)$ & 1 \\
\hline Possession of weapons & $0(0)$ & 0 & $1(2)$ & 1 & $0(0)$ & 0 \\
\hline Other & $3(7)$ & 14 & 2 (5) & 5 & 2 (5) & 24 \\
\hline Total & 15 (37) & 241 & $19(45)$ & 278 & $16(43)$ & 764 \\
\hline
\end{tabular}

for the injectable heroin group (mean 0.27) than the injectable and oral methadone groups (mean 0.24 in both groups), but not significantly so $(P=0.8475)$.

\section{Cost-effectiveness}

Figure 1(a) shows the scatter plot of the bootstrapped total cost (intervention plus all health, social service and criminal justice resources) and effectiveness (QALYs) pairs for injectable heroin $v$. oral methadone. The ICER (denoted by a square) and the majority of the scatter points are located in the south-east quadrant of the cost-effectiveness plane, indicating that injectable heroin is associated with lower total costs (below the x-axis) and better effects (to the right of the $y$-axis) than oral methadone, and is said to be dominant. The CEAC in Fig. 1(b) demonstrates there is a higher probability of injectable heroin being more costeffective than oral methadone irrespective of a decision maker's willingness to pay for an additional QALY. At a willingness to

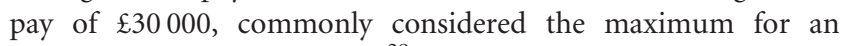
additional QALY in the $\mathrm{UK},{ }^{29}$ there is a $70 \%$ probability that injectable heroin is more cost-effective than oral methadone. The results comparing injectable with oral methadone are similar, as illustrated in Fig. 2.

Comparing all three treatments, oral methadone was dominated by both injectable heroin and methadone, and was excluded from further analysis. Supervised injectable heroin was associated with higher total costs per participant than supervised injectable methadone (bootstrapped incremental cost $£ 2931$ ) but better effects (bootstrapped incremental QALYs 0.05). The scatter points (Fig. 3(a)) fall mainly within the north-east quadrant of the cost-effectiveness plane, indicating a trade-off where additional effects of injectable heroin can only be gained at greater cost. The associated CEAC (Fig. 3(b)) demonstrates that at low levels of willingness to pay for an additional QALY, there is a greater

Table 2 Total costs over the 26-week follow-up period

\begin{tabular}{|c|c|c|c|c|}
\hline & \multicolumn{3}{|c|}{ Mean (s.d.) per participant, $f$} & \multirow[b]{2}{*}{ ANOVA $P^{a}$} \\
\hline & $\begin{array}{l}\text { Supervised injectable } \\
\text { heroin }(n=41)\end{array}$ & $\begin{array}{l}\text { Supervised injectable } \\
\text { methadone }(n=42)\end{array}$ & $\begin{array}{l}\text { Optimised oral } \\
\text { methadone }(n=37)\end{array}$ & \\
\hline Intervention costs & 8995 (2907) & $4674(2105)$ & $2569(1082)$ & $<0.0001$ \\
\hline Drug costs & $1814(862)$ & 720 (383) & 205 (114) & $<0.0001$ \\
\hline Clinic costs & $5578(1872)$ & $2571(1307)$ & 1047 (493) & $<0.0001$ \\
\hline Weekly case management & $1026(628)$ & $984(663)$ & $922(615)$ & $<0.0001$ \\
\hline Urine tests & 577 (198) & $398(169)$ & $394(170)$ & $<0.0001$ \\
\hline Other service use & $2632(5603)$ & 2745 (3093) & $2274(2644)$ & 0.097 \\
\hline Staffed accommodation & 493 (1186) & $660(1081)$ & 783 (1121) & 0.510 \\
\hline Hospital services & $1380(4362)$ & $486(1077)$ & $622(1419)$ & 0.129 \\
\hline Community services & $317(645)$ & 719 (1044) & $618(623)$ & 0.051 \\
\hline Criminal justice services & 442 (1139) & $880(2613)$ & 251 (934) & 0.302 \\
\hline Crimes committed & $1782(3844)$ & 3526 (8939) & 10962 (40985) & 0.378 \\
\hline Total cost over 26 weeks & $13410(5962)$ & 10945 (9235) & 15805 (42908) & 0.637 \\
\hline Total cost per week & $457(195)$ & $373(324)$ & $529(1419)$ & 0.603 \\
\hline
\end{tabular}



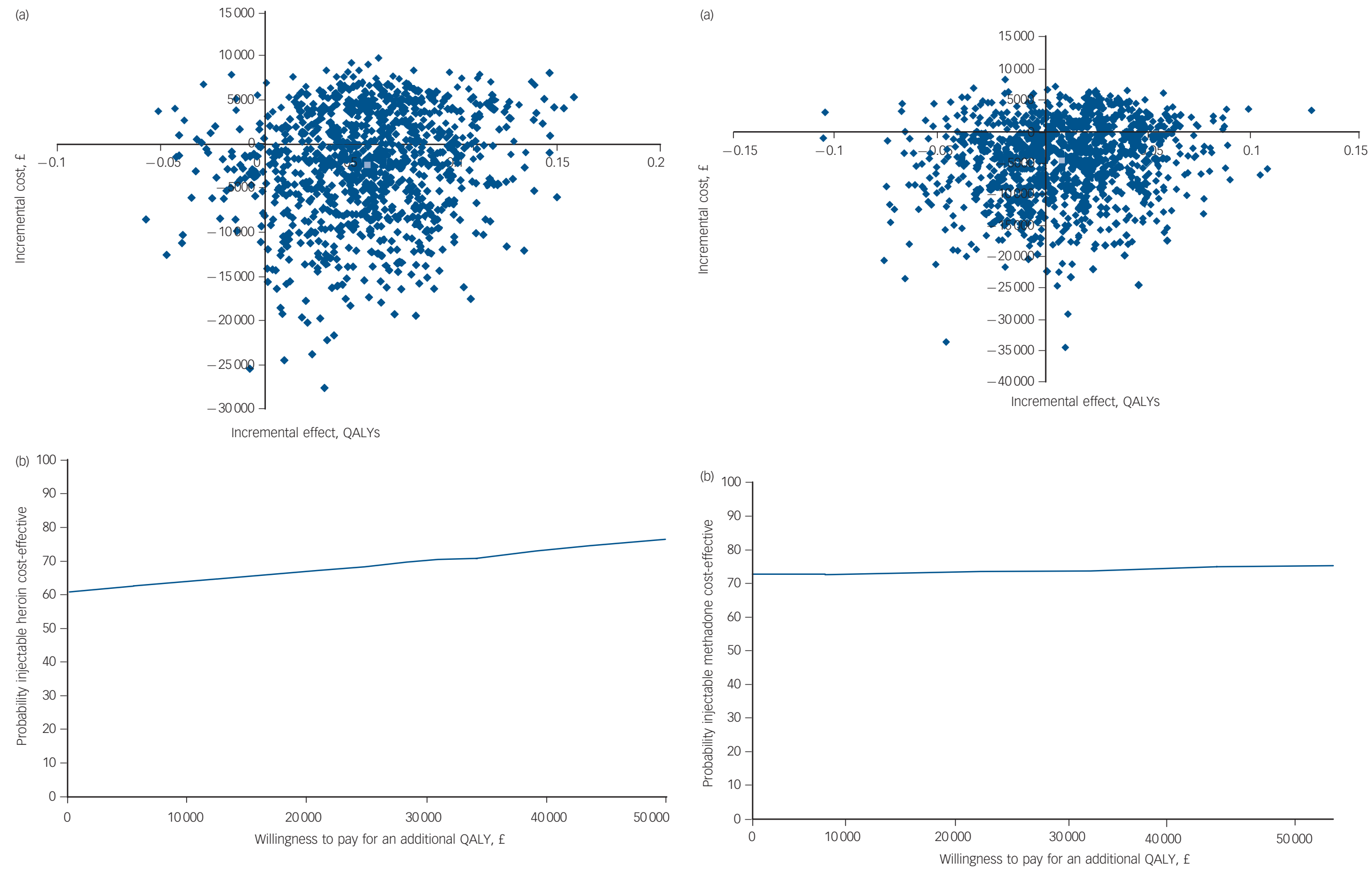

Fig. 1 Supervised injectable heroin $v$. optimised oral methadone (a) bootstrapped cost and

effectiveness pairs for quality-adjusted life-years (QALYS) and (b) cost-effectiveness acceptability

Fig. 2 Supervised injectable methadone $v$. optimised oral methadone (a) bootstrapped cost and effectiveness pairs for quality-adjusted life-years (QALYS) and (b) cost-effectiveness acceptability curve for QALYS. 


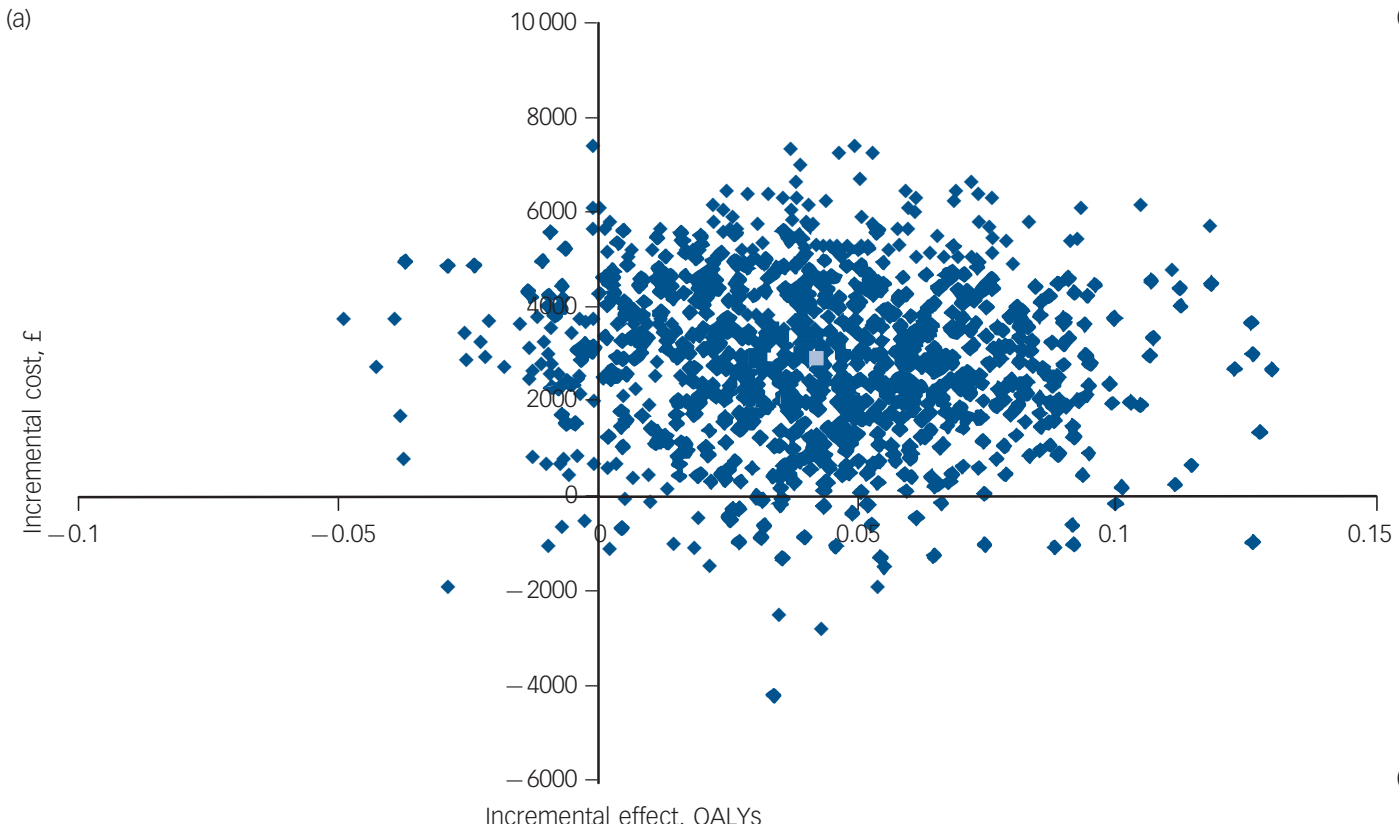

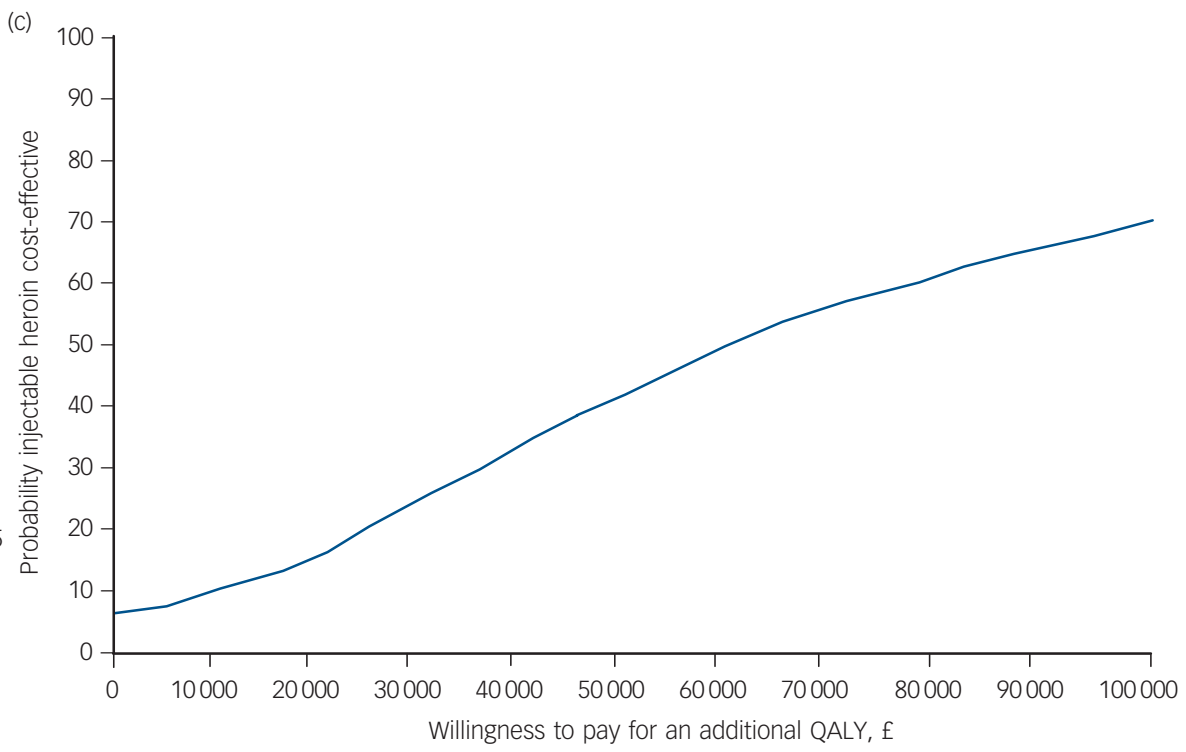

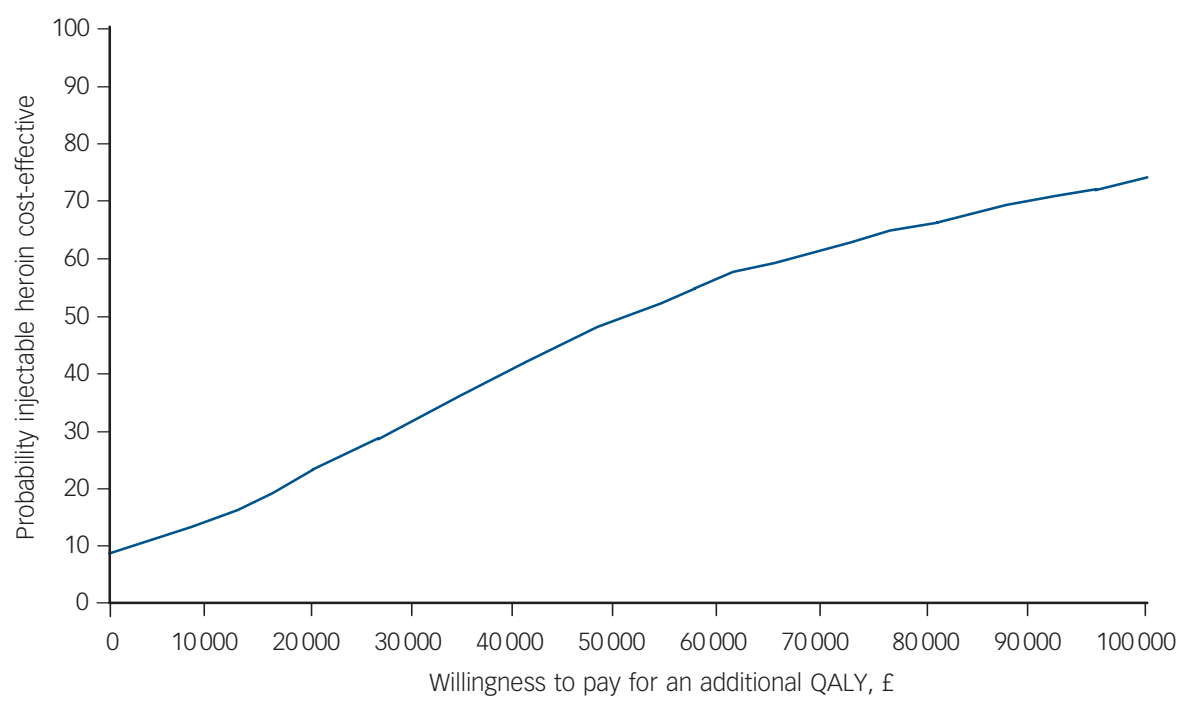

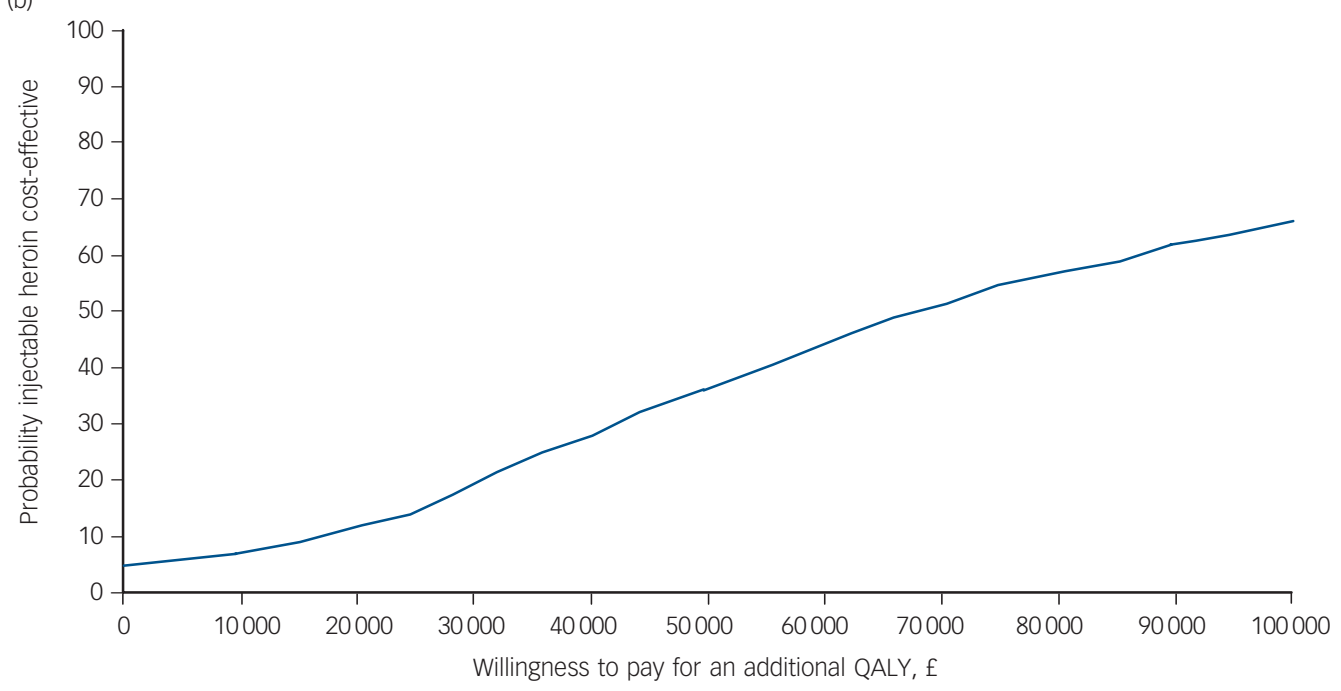

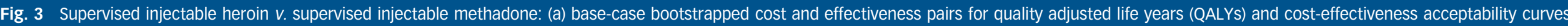




\begin{tabular}{|c|c|c|c|c|c|c|}
\hline & \multicolumn{2}{|c|}{$\begin{array}{l}\text { Supervised injectable heroin } \\
\qquad(n=43)\end{array}$} & \multicolumn{2}{|c|}{$\begin{array}{l}\text { Supervised injectable methadone } \\
\qquad(n=42)\end{array}$} & \multicolumn{2}{|c|}{$\begin{array}{l}\text { Optimised oral methadone } \\
\qquad(n=42)\end{array}$} \\
\hline & $\begin{array}{l}\text { Weeks since } \\
\text { baseline }\end{array}$ & Mean (s.d.) & $\begin{array}{l}\text { Weeks since } \\
\text { baseline }\end{array}$ & Mean (s.d.) & $\begin{array}{l}\text { Weeks since } \\
\text { baseline }\end{array}$ & Mean (s.d.) \\
\hline \multicolumn{7}{|l|}{ EQ-5D tariff } \\
\hline Baseline & 0.00 & $0.43(0.46)$ & 0.00 & $0.39(0.51)$ & 0.00 & $0.38(0.47)$ \\
\hline 14-week follow-up & 16.50 & $0.47(0.48)$ & 16.67 & $0.39(0.50)$ & 16.15 & $0.40(0.44)$ \\
\hline 26-week follow-up & 29.49 & $0.50(0.45)$ & 29.71 & $0.47(0.53)$ & 29.91 & $0.46(0.45)$ \\
\hline Quality-adjusted life-years & & $0.27(0.25)$ & & $0.24(0.28)$ & & $0.24(0.25)$ \\
\hline
\end{tabular}

probability of injectable methadone being the more cost-effective of the two strategies (probability injectable methadone more cost-effective at $£ 30000$ per QALY $80 \%$, injectable heroin $20 \%$ ). Supervised injectable heroin becomes the more likely to be

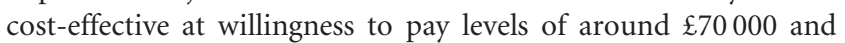
above, substantially above the maximum threshold of $£ 30000$ per QALY.

\section{Sensitivity analysis}

The base-case analysis applied the price paid by the RIOTT clinics for pharmaceutical injectable heroin at the point the trial ended ( $£ 12.50$ per $500 \mathrm{mg}$ preparation). Although this price represents the most efficient market price at that time, any decision to increase the availability of injectable heroin in the UK may have an impact on the long-term supply cost. Increased demand will commonly influence production processes and encourage additional suppliers into the market, thus reducing costs through productive efficiencies and economies of scale. Discussions with suppliers suggest current supply may be feasible at a cost of $£ 10$ per $500 \mathrm{mg}$, and future supply on a wider scale could see the price fall to $£ 7$ per $500 \mathrm{mg}$. Applying a price of $£ 10$ per $500 \mathrm{mg}$ (Fig. 3(c)), supervised injectable methadone remains the more likely to be cost-effective at a maximum willingness to pay for a QALY of $\mathfrak{E 3 0 0 0 0 ~ ( p r o b a b i l i t y ~ i n j e c t a b l e ~ m e t h a d o n e ~ m o r e ~ c o s t - ~}$ effective $75 \%$, injectable heroin $25 \%$ ). The results are the same when applying $\mathfrak{E} 7$ per $500 \mathrm{mg}$ (Fig. 3(d)), although the probability of injectable methadone being the more cost-effective strategy at a

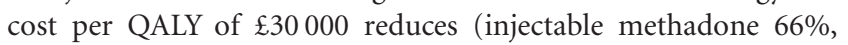

injectable heroin 33\%). Threshold analysis suggests that the price of pharmaceutical injectable heroin would need to fall to $\mathfrak{E} 2$ per $500 \mathrm{mg}$ preparation before there was a greater probability of injectable heroin being the more cost-effective option at a cost per QALY of $\mathfrak{E 3 0} 000$ than injectable methadone.

The base-case analysis takes a broad cost perspective which includes the criminal justice sector, known to be important in substance misusing populations. ${ }^{30}$ This is contrary to the NHS/ personal social services reference case perspective preferred by NICE for UK guidelines. ${ }^{27}$ Applying this narrower perspective, oral methadone was found to dominate both injectable heroin and methadone as a result of lower health and social service costs alongside only small differences in outcome between groups (Fig. 4).

\section{Discussion}

\section{Cost-effectiveness}

Cost-effectiveness analysis from a broad perspective demonstrates that injectable treatments dominate oral methadone treatment for chronic refractory heroin addiction, even when efforts are made to optimise oral methadone treatment. However, cost-effectiveness is being driven by savings in the criminal justice sector, not the health sector, with injectable treatments being cost-ineffective compared with oral methadone when the narrower health and social service perspective is taken. These findings are supported by similar research in The Netherlands comparing co-prescribed heroin and methadone with methadone maintenance alone, which

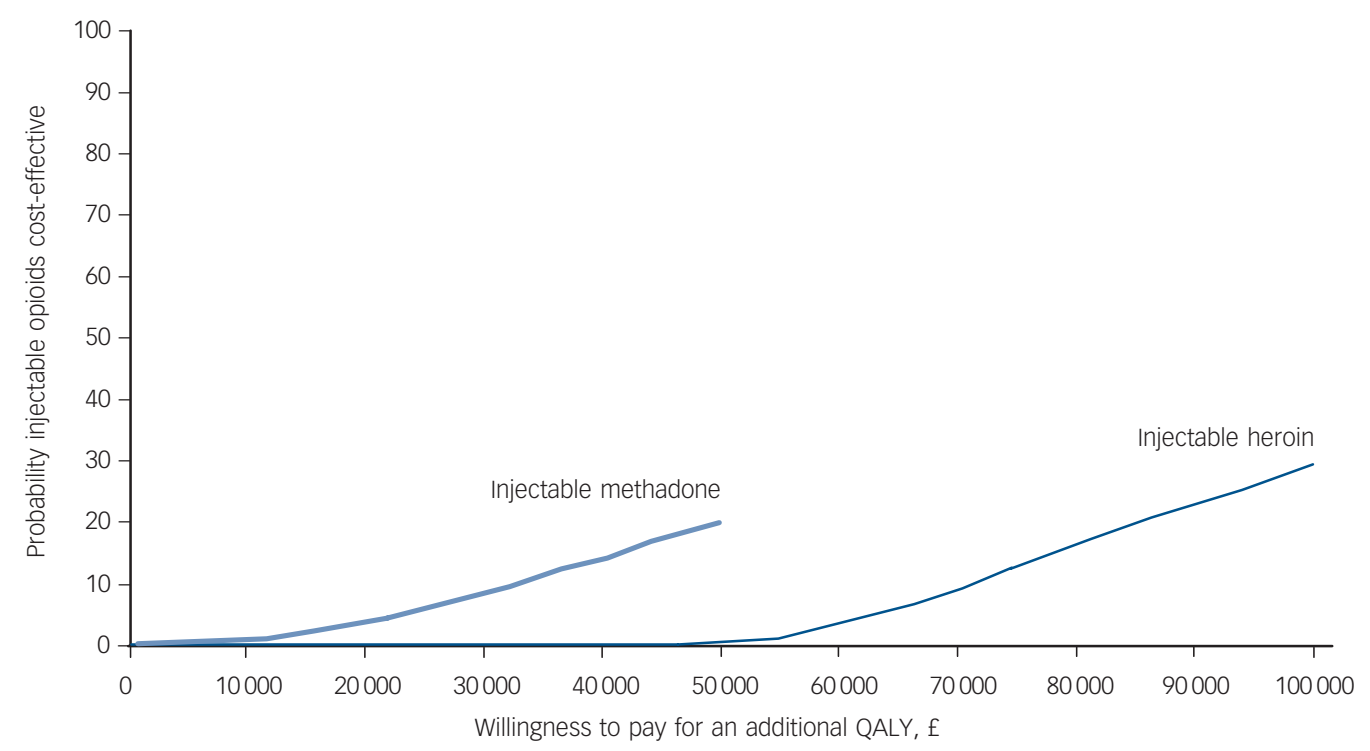

Fig. 4 Supervised injectable heroin and supervised injectable methadone $v$. optimised oral methadone cost-effectiveness acceptability curve for quality adjusted life years (QALYS) - National Health Service/personal social services perspective. 
found that the addition of heroin generated better outcomes, and the additional treatment costs were offset by lower criminal justice costs. $^{31}$

Since reductions in crime and savings to the criminal justice sector are important policy aims, ${ }^{32}$ it is appropriate to consider these broader costs in evaluations involving populations where crime is a relevant resource burden, as acknowledged in NICE guidelines that support the presentation of broader perspectives where costs to other government bodies are believed to be significant. ${ }^{27}$ A narrow perspective is without theoretical foundation ${ }^{33}$ and, in this instance, would support an intervention that saved health and social care resources compared with the injectable alternatives, but was less effective, associated with higher levels of criminal activity and, overall, placed a greater burden on the public sector purse. Focusing on the more appropriate broader perspective, these findings suggest that injectable alternatives should be preferred to oral treatments but that some compensation may be needed to support clinics in the provision of the more expensive, but also more cost-effective, treatments.

Clinical evidence from the RIOTT study suggests that supervised injectable heroin may be more effective than supervised injectable methadone. ${ }^{7}$ However, the economic evidence, although supporting the cost-effectiveness of both injectable opiate treatments compared with oral methadone in this treatment-resistant population, does not support the costeffectiveness of injectable heroin compared with injectable methadone. Relative cost-effectiveness was found to be sensitive to the price of pharmaceutical diamorphine, but the price would have to fall considerably before injectable heroin became the more likely of the two options to be cost-effective. Budgetary pressures are also a factor for consideration. Detailed micro-costing found injectable methadone to be approximately twice the cost of optimised oral methadone, while injectable heroin was 3.5 times the cost. Thus, the provision of supervised injectable heroin is also likely to be dependent on clinical funding.

\section{Limitations}

The study is limited in a number of ways. First, the large cost differences between groups did not reach statistical levels of significance, due to high levels of variance in the cost of crimes, resulting from small numbers of prolific offenders. To achieve statistical significance, a much larger sample would be needed. However, the cost of such a trial may be prohibitive. Instead, a decision-making approach was taken which explored the likelihood of one treatment being more cost-effective than another, given the data currently available. ${ }^{25}$

Second, the results are limited by reliance on self-reported levels of criminal activity. Although more accurate data on recorded arrests, convictions and incarcerations may be available, ${ }^{34}$ such data do not measure the true economic impact of criminal activity, since costs are associated with all crimes committed, not just those involving arrest or conviction. ${ }^{20}$

Third, the study is limited by a relatively short follow-up which may not be long enough to capture the full economic implications in this chronic population. In particular, the appropriateness of focusing on generic measures of outcome, such as QALYs, which are generally preferred by economists and policymaking bodies, ${ }^{28}$ in a population still primarily dependent on heroin is unclear. Instead, QALYs may be of more value in longer-term analyses. Future research to model the long-term consequences of treatment in this population may be of particular value.

Finally, the results presented here are generalisable to chronic heroin addiction populations who fail to benefit from conventional treatment and continue to inject heroin on a regular basis. They may be of less relevance to populations who are treated successfully with conventional oral methadone maintenance. In addition, the results may not reflect standard clinical practice in relation to the oral methadone arm of the trial, which was optimised in a way that may not happen in all routine clinics. However, this provided a more stringent test of the injectable opioid treatments, since in routine practice the oral methadone group may have demonstrated poorer outcomes than those reported here.

\section{Implications}

Our results do not support the continuing provision of oral methadone maintenance treatment alone for chronic refractory heroin addiction, despite the relatively low treatment costs in comparison to injectable alternatives. However, policy makers will need to compensate clinics for providing a more expensive service that generates cost savings primarily for the criminal justice sector. The choice of which injectable treatment to provide is less clear. There is currently evidence to suggest superior effectiveness of supervised injectable heroin but at a cost that policy makers may find unacceptable. Future research should consider the use of decision analytic techniques to model expected costs and benefits of the treatments under alternative assumptions regarding future demand for and supply of, and thus cost of, pharmaceutical diamorphine and indeed methadone and, perhaps most importantly, longer-term evidence of impact on quality of life.

Sarah Byford, PhD, Barbara Barrett, PhD, Centre for the Economics of Mental and Physical Health, Institute of Psychiatry, King's College London, UK; Nicola Metrebian, PhD, Addictions Department, National Addiction Centre, Institute of Psychiatry, King's College London, UK; Teodora Groshkova, PhD, European Monitoring Centre for Drugs and Drug Addiction, Lisbon, Portugal; Maria Cary, MSC Monitoring Centre for Drugs and Drug Addiction, Lisbon, Portugal; Maria Cary, MSC,
Centre for the Economics of Mental and Physical Health, Institute of Psychiatry, King's Centre for the Economics of Mental and Physical Health, Institute of Psychiatry, King's
College London, UK; Vikki Charles, MA, Addictions Department, National Addiction Centre, Institute of Psychiatry, King's College London, UK; Nicholas Lintzeris, PhD, The Langton Centre, South Eastern Sydney Local Health District, NSW Health, Australia; John Strang, MD, Addictions Department, National Addiction Centre, Institute of Psychiatry, King's College London, UK

Correspondence: Sarah Byford, Centre for the Economics of Mental and Physical Health, Box P024, Institute of Psychiatry, De Crespigny Park, London SE5 8AF, UK. Email: s.byford@kcl.ac.uk

First received 6 Mar 2012, final revision 8 May 2013, accepted 15 May 2013

\section{Funding}

Funded by the Community Fund (Big Lottery Research section), through Action on Addiction.

\section{References}

1 Gossop M, Marsden J, Stewart D, Kidd T. The National Treatment Outcome Research Study (NTORS): $4-5$ year follow-up results. Addiction 2003; 98 : 291-303.

2 Lintzeris N. Prescription of heroin for the managment of heroin dependence. CNS Drugs 2009; 23: 463-76.

3 Strang J, Groshkova T, Metrebian N. New Heroin-Assisted Treatment: Recent Evidence and Current Practices of Supervised Injectable Heroin Treatment in Europe and Beyond. European Monitoring Centre for Drugs and Drug Addiction, 2011

4 Perneger TV, Giner F, del Rio M, Mino A. Randomised trial of heroin maintenance programme for addicts who fail in conventional drug treatments. BMJ 1998; 317: 13-8.

5 Haasen C, Verthein U, Degkwitz P, Berger J, Krausz M, Naber D. Heroinassisted treatment for opioid dependence: randomised controlled trial. Br J Psychiatry 2007; 191: 55-62.

6 Oviedo-Joekes E, Brissette S, Marsh DC, Lauzon P, Guh D, Anis A, et al. Diacetylmorphine versus methadone for the treatment of opioid addiction. N Engl J Med 2009; 361: 777-86. 
7 Strang J, Metrebian N, Lintzeris N, Potts L, Carnwath T, Mayet S, et al Supervised injectable heroin or injectable methadone versus optimised oral methadone as treatment for chronic heroin addicts in England after persistent failure in orthodox treatment (RIOTT): a randomised trial. Lancet 2010; 375: 1885-95.

8 Royal Pharmaceutical Society of Great Britain. British National Formulary 55 (March). BMJ Group and RPS Publishing, 2008.

9 Lintzeris M, Strang J, Metrebian N, Byford S, Hallam C, Lee S, et al. Methodology for the Randomised Injecting Opioid Treatment Trial (RIOTT): evaluating injectable methadone and injectable heroin treatment versus optimised oral methadone treatment in the UK. Harm Reduct J 2006; 3: 28.

10 Strang J, Marsden J, Cummins M, Byford S, Hallam C, Lee S, et al. Randomized trial of supervised injectable versus oral methadone maintenance: report of feasibility and 6-month outcome. Addiction 2000; 95: 1631-45.

11 Gordon L, Tinsley L, Godfrey C, Parrott S. The economic and social costs of Class A drug use in England and Wales, 2003/04. In Measuring Different Aspects of Problem Drug Use: Methodological Developments (2nd edn) (eds N Singleton, R Murray, L Tinsley): 41-5. Home Office, 2006.

12 Brooks R. EuroQol: the current state of play. Health Policy 1996; 37: 53-72.

13 Richardson G, Manca A. Calculation of quality adjusted life years in the published literature: a review of methodology and transparency. Health Econ 2004; 13: 1203-10.

14 van der Zanden BP, Dijkgraaf MGW, Blanken P, de Borgie CAJM, van Ree JM, Van den Brink W. Validity of the EQ-5D as a generic health outcome instrument in a heroin-dependent population. Drug Alcohol Depend 2006; 82: 111-8.

15 Barrett B, Byford S, Crawford MJ, Patton R, Drummond C, Henry JA, et al. Cost-effectiveness of screening and referral to an alcohol health worker in alcohol misusing patients in an accident and emergency department: a decision-making approach. Drug Alcohol Depend 2006; 81: 47-54.

16 Drummond M, Sculpher M, Torrance GW, O'Brien B, Stoddart GL. Methods for the Economic Evaluation of Health Care Programmes. Oxford University Press, 2005.

17 Paterson S, Lintzeris N, Mitchell TB, Cordero R, Nestor L, Strang J. Validation of techniques to detect illicit heroin use in patients prescribed pharmaceutical heroin for the management of opioid dependence. Addiction 2005; 100: 1832-9.

18 Department of Health. NHS Reference Costs 2008. Department of Health 2008
19 Curtis L. The Unit Costs of Health and Social Care 2008. University of Kent at Canterbury, Personal Social Services Research Unit, 2008.

20 Dubourg R, Hamed J. The Economic and Social costs of Crime against Individuals and Households 2003/04. Home Office, 2005.

21 Metropolitan Police. MPS Ready Reckoner. Metropolitan Police Authority, 2000.

22 HM Prison Service. Prison Service Annual Report and Accounts 2008. TSO (The Stationery Office), 2009.

23 Barber JA, Thompson SG. Analysis of cost data in randomized trials: an application of the non-parametric bootstrap. Stat Med 2000; 19: 3219-36.

24 Johannesson $\mathrm{M}$, Weinstein $\mathrm{MC}$. On the decision rules of cost-effectiveness analysis. J Health Econ 1993; 12: 459-67.

25 Claxton $\mathrm{K}$. The irrelevance of inference: a decision-making approach to the stochastic evaluation of health care technologies. J Health Econ 1999; 18: 341-64.

26 Fenwick E, Byford S. A guide to cost-effectiveness acceptability curves. Br J Psychiatry 2005; 187: 106-8.

27 National Institute for Health and Clinical Excellence. Guide to the Methods of Technology Appraisal. NICE, 2008.

28 Hjelmgren J, Berggren F, Andersson F. Health economic guidelinessimilarities, differences and some implications. Value Health 2001; 4 225-50.

29 Appleby J, Devlin N, Parkin D. NICE's cost effectiveness threshold: how high should it be? BMJ 2007; 335: 359.

30 Cartwright WS. Cost-benefit analysis of drug treatment services: review of the literature. J Ment Health Policy Econ 2000; 3: 11-26.

31 Dijkgraaf MGW, van der Zanden BP, de Borgie CAJM, Blanken P, van Ree JM, Van den Brink W. Cost utility analysis of co-prescribed heroin compared with methadone maintenance treatment in heroin addicts in two randomised trials. BMJ 2005; 330: 1297-302.

32 Home Office. A New Approach to Fighting Crime. Home Office, 2011.

33 Johannesson $\mathrm{M}$. A note on the depreciation of the societal perspective in economic evaluation of health care. Health Policy 1995; 33: 59-66.

34 Chambers J, Yiend J, Barrett B, Burns T, Doll H, Fazel S, et al. Outcome measures used in forensic mental health research: a structured review. Crim Behav Ment Health 2009; 19: 9-27. 